Volume-IX, Issue-01, January-June, 2014

\title{
Factors Affecting Consumers' Purchasing Decision of Toiletries Products: An Empirical Study on Square Toiletries in Khulna City
}

\author{
MD. RABIUL ISLAM* \\ RUMANA PERVEEN** \\ S. M. MONIRUL ISLAM ${ }^{* * *}$ \\ BULBUL AHAMED ${ }^{* * * *}$
}

\begin{abstract}
This study is an attempt to identify the factors which affect consumers in purchasing toiletries products in Khulna City, Bangladesh. Data were collected from Consumers of the city using structured questionnaire. More or less a random sampling method was applied to collect response from 250 consumers from which 197 found free from errors; those respondents were used for the ultimate study. Factor analysis and ANOVA with SPSS were applied for data analysis. This study has found that the factors consumers consider for their purchasing decisions are brand image, cost and commitments, distinctiveness, prestige, customer relationship. Except distinctiveness, individuals with various education levels do not show different perceptions on these identified factors.
\end{abstract}

Key Words: Toiletries products, Factor analysis, purchasing decisions

\section{INTRODUCTION}

Competition is a buzz-word in new era of globalization. Different companies are trying to satisfy the needs of target consumers by offering innovative products. Toiletries products are also playing a vital role in our everyday life. People are also conscious about the improvement of their living standard in so many aspects. Now-a-days, in respect of this awareness, toiletries products have already become almost essential needs of the people. At present, more than 55

\footnotetext{
* Assistant Professor of CSE, Department of Business Administration, Northern University Bangladesh. E-mail: rabi_cpi@yahoo.com

** Senior Lecturer in Marketing, Department of Business Administration, Northern University Bangladesh

*** Assistant Professor of Marketing Department of Business Administration, Northern University Bangladesh. E-mail: smoni_nub@yahoo.com

**** Assistant Professor of CSE, Department of CSE, Northern University Bangladesh. E-mail: bulbu12767@gmail.com
} 
products covering a wide range of categories like skin care, hair care, oral care, baby care, fabric care, scourers, and male grooming are being produced by different manufacturing companies; as well as these products are being imported from different countries in Bangladesh. Considering the significance this study has strived to explore the factors that affect purchasing decisions of the consumers in purchasing the toiletries products of different companies.

This research tries to explore the factors that influence the individual consumers to select their toiletries products. In this article descriptive statistics have been estimated and factor analysis has been performed to identify the factors that actually motivate or affect consumers in selecting toiletries products of different companies.

\section{LITERATURE REVIEW}

T. H. Al-Gahaifi , J. Světlík (2011) identified that there is a high influence of price, occasions, and time of purchase on Yemeni consumer, while display, sorting, and the location of seller suggests moderate influence. The influence was low for word of mouth in case of buying of vegetables. This particular study is geographically focused on Yemeni consumers and fitted on vegetable products. Yakup \& Jablonsk (2012) conducted a study on Integrated Approach to Factors Affecting Consumers Purchase Behavior in Poland. In the research 500 consumers were interviewed; it tried to relate the factors affecting the consumers' behaviors such as age and life times, occupation, lifestyle and personality of consumers in Poland. The study did not focus on any specific product or industry. It was found that factors affecting consumer buying differ from industry to industry; the intensity (weight) of a particular factor differ between products and industries. Tinne, W. S. (2011), conducted a study titled on Factors Affecting Impulse Buying Behavior of Consumers at Superstores in Bangladesh. In this research the author explored the impact of various variables like discount offer, various scheme, promotional activities, retail store offer, display of product, behavior of sales person, popularity of product, influence of reference group, income level of Consumers' and festival season, on consumer impulse buying behavior. The sample size was only 50 consumers taken from two super stores in Dhaka city. This study is based on very small sample which may not reflect the population characteristics. Chan Yew Ling (2013) explored the drivers (i.e. factors) and their moderating variable that influence consumers purchasing intention on green personal-care product. The results revealed that environmental 
attitudes and self-efficacy were important drivers that influence purchasing of green personal care products. In addition, it was found that willingness of consumers to pay more on green personal care products was moderating the relationship between environmental attitudes and purchasing intention. The author emphasized on a specific industry (green personal care products). So the study of another industry (i.e. toiletries) may come up different findings. Jennifer Keeling Bond, Dawn Thilmany, and Craig Bond (2009) identified the factors that influence consumer choice of fresh produce buying decision. They found that availability of fresh, superior, vitamin-rich, and locally-grown produce at market locations are essential to create loyalty of current consumers through booth displays, ads in magazines, radio spots, and electronic newsletters. The study is focused on influence of promotional factors such as product display, advertisement etc. on consumer choice of agro-based products. Leila Haghshenal et al.,(2013) presents us with a conceptual study to identify different factors affecting consumer behavior and purchase-decision. The study revealed that buying decision process is influenced by controllable and uncontrollable factors. The factors listed are social group, and individual psychological factors, and situational factors, value, performance, benefit, marketing mix. Rao and Sharma (2010) used 312 students of Delhi and found employee's courtesy, parking facility, loyalty programs, brand name, security system and low charges influence selection of bank. Other factors, which have importance are the responsiveness, value added services and convenience. Assurance factors, such as speedy services, good rate of interest and zero balance account facility are also significant in motivating the choice of a bank. Reaz Uddin and Tarun Kanti Bose (2013) explored the factors that affect the success of SME (Small and Medium Enterprise) in Bangladesh. Business plan, channel of distribution, management skills and government support are identified as statistically significant in determining success of SMEs in Khulna City. Rotated components matrix and regression statistics were applied to find out the determining factors. Waleed AIGhaith. Louis Sanzogni and Sandhu (2010) identified the factors that influence the online services in Saudi Arabia and revealed that perceived complexity is the most important factor that affects the e-service adoption in Saudi Arabia. Quality of the internet and its relative advantage also affected e-service usage and adoption in Saudi Arabia. Data were collected from 651 respondents for this purpose. 


\section{OBJECTIVES OF THE RESEARCH}

The main objective of this research is to identify the factors that influence individual consumers to purchase the toiletries products. The specific objectives are:

i. To identify factors which affect the purchasing decision of the consumers.

ii. To identify whether individuals with different education levels show difference in opinions with regard to the determining factors.

\section{RESEARCH METHODOLOGY}

For empirical estimates primary data were used. Interview technique was used with structured questionnaire for the collection of primary data. Sort of a random sampling was used to select the sample units from different consumers in Khulna city who were using Square Toiletries products particularly soap, toothpaste, shampoo and hair oil. A total of 197 consumers were taken as the sample of the survey and sample consumers were selected from different retail and super stores of Khulna city who have shown interest in the survey. The respondents were asked questions after completion of their purchase. Likert-type five point scale has been used where value 1 is assigned for the answer strongly disagree, 2 for disagree, 3 for neutral, 4 for agree and 5 for strongly agree answer for each question. The questionnaire consisted of two parts. The first section was designed to collect general information about the consumers and in the second part was designed to screen out the factors that influence consumers to purchase the products. Secondary data have been collected also from different articles and websites. 197 consumers were selected and factor analysis was conducted to determine significance among the variables. Keiser-Meyer-Olkin measure of sampling adequacy (Kaiser, 1970) and Bartlett's test of Sphericity (Bartlett 1954) were used for the justification of factor analysis. Principal component analysis and component matrix were used to estimate causal factors. Factor loading was identified using a principal component analysis extraction method with a varimax with Kaiser Normalization rotation. Multiple regression techniques were used to identify statistically significant factors. For all analyses SPSS software version 16.0 was used. 


\section{DATA ANALYSIS AND FINDINGS}

TABLE 1

FOUR MAJOR SOCIO-ECONOMIC ASPECTS OF THE RESPONDENTS

\begin{tabular}{|l|l|l|l|}
\hline \multirow{4}{*}{ Gender } & N=197 & Frequency & Percentage (\%) \\
\hline \multirow{5}{*}{ Age (years) } & Male & 185 & 93.9 \\
\cline { 2 - 4 } & Female & 12 & 6.1 \\
\cline { 2 - 4 } & Below 25 & 39 & 19.8 \\
\cline { 2 - 4 } & $25-34$ & 69 & 35 \\
\cline { 2 - 4 } Education Level & $35-44$ & 75 & 38.1 \\
\cline { 2 - 4 } completed & $45-54$ & 11 & 5.6 \\
\cline { 2 - 4 } & Above 54 & 3 & 1.5 \\
\cline { 2 - 4 } & Under SSC & 16 & 8.1 \\
\cline { 2 - 4 } & SSC & 29 & 14.7 \\
\cline { 2 - 4 } & Graduate & 56 & 28.7 \\
\cline { 2 - 4 } Occupation & Oostgraduate & 41 & 28.2 \\
\cline { 2 - 4 } & Businessman & 44 & 22.3 \\
\cline { 2 - 4 } & Service Holder & 39 & 19.8 \\
\cline { 2 - 4 } & Housewife & 8 & 4.1 \\
\cline { 2 - 4 } & Professionals & 50 & 25.4 \\
\cline { 2 - 4 } & Others & 56 & 28.4 \\
\hline
\end{tabular}

Source: Own Field Survey, October-November, 2013

Table 1 indicates that 93.9 percent of the respondents are male and 6.1 percent are female. The age level of 19.8 percent respondents is below 25 years. The age of 35 percent respondents is between 25-34 years, 38.1 percent between 35-44 years, 5.6 percent between $45-54$ years and only 1.5 percent is above 54 years. 28.7 percent and 28.2 percent respondents have passed HSC and graduate level respectively. 21 percent respondents have completed their postgraduate level and 14.7 percent have passed SSC. Only 8.1 percent respondents are under SSC. 25.4 percent respondents are professionals and 22.3 percent, 19.8 percent and 4.1 percent are businessman, service holder and housewife respectively.28.4 percent respondents are engaged in other works. 
TABLE 2

KMO AND BARTLETT'S TEST

\begin{tabular}{|l|l|l|}
\hline \multicolumn{3}{|c|}{ KMO and Bartlett's Test } \\
\hline Kaiser-Meyer-Olkin Measure of Sampling Adequacy & .894 \\
\hline \multirow{2}{*}{ Bartlett's Test of Sphericity } & Approx. Chi-Square & 4.1683 \\
\cline { 2 - 3 } & df & 378 \\
\cline { 2 - 3 } & Sig. & .000 \\
\hline
\end{tabular}

Source: Own Field Survey, October-November, 2013

The value of KMO is 0.894 which is more than 0.6. It signifies that data are sufficient for applying factor analysis. Bartlett Test is applied to identify whether variables used for factor analysis are related. The results show that relationship exist among variables $(\mathrm{p}<.05)$.

TABLE 3

TOTAL VARIANCE EXPLAINED

\begin{tabular}{|c|c|c|c|c|c|c|c|c|c|}
\hline \multirow[b]{2}{*}{ Component } & \multicolumn{3}{|c|}{ Initial Eigenvalues } & \multicolumn{3}{|c|}{$\begin{array}{c}\text { Extraction Sums of Squared } \\
\text { Loadings }\end{array}$} & \multicolumn{3}{|c|}{$\begin{array}{c}\text { Rotation Sums of Squared } \\
\text { Loadings }\end{array}$} \\
\hline & Total & $\begin{array}{c}\% \text { of } \\
\text { Variance }\end{array}$ & $\begin{array}{c}\text { Cumulative } \\
\%\end{array}$ & Total & $\begin{array}{c}\% \text { of } \\
\text { Variance }\end{array}$ & $\begin{array}{c}\text { Cumulative } \\
\%\end{array}$ & Total & $\begin{array}{c}\% \text { of } \\
\text { Variance }\end{array}$ & $\begin{array}{c}\text { Cumulative } \\
\%\end{array}$ \\
\hline 1 & 12.160 & 45.038 & 45.038 & 12.160 & 45.038 & 45.038 & 4.651 & 17.227 & 17.227 \\
\hline 2 & 2.784 & 10.312 & 55.350 & 2.784 & 10.312 & 55.350 & 4.586 & 16.987 & 34.214 \\
\hline 3 & 1.471 & 5.448 & 60.799 & 1.471 & 5.448 & 60.799 & 4.216 & 15.616 & 49.831 \\
\hline 4 & 1.244 & 4.608 & 65.406 & 1.244 & 4.608 & 65.406 & 3.036 & 11.244 & 61.075 \\
\hline 5 & 1.047 & 3.879 & 69.285 & 1.047 & 3.879 & 69.285 & 2.217 & 8.210 & 69.285 \\
\hline
\end{tabular}

Source: Own Field Survey, October-November, 2013

The above Table 3 shows outcome of extraction under principal component analysis. This Table initially shows all the factors extracted from principle component analysis but according to the previous literature factors whose eigen value is more than one is considered appropriate for explaining the variation in purchasing decisions. It is seen in the above Table that only five factors have eigen values greater that one thus selected finally. Those five factors explain almost 70 percent variation in purchasing decisions of consumers. 
TABLE 4

ROTATED COMPONENT MATRIX

\begin{tabular}{|l|c|c|c|c|c|}
\hline & \multicolumn{5}{|c|}{ Component } \\
\hline & $\begin{array}{c}\text { Brand } \\
\text { Image }\end{array}$ & $\begin{array}{c}\text { Cost \& } \\
\text { Commitment }\end{array}$ & $\begin{array}{c}\text { Distinctiv } \\
\text { eness }\end{array}$ & Prestige & Relationship \\
\hline Meaning of brand & .799 & & & & \\
\hline Suitability of brand & .787 & & & & \\
\hline Positive and warm feelings & .734 & & & & \\
\hline Trustworthiness & .670 & & & & \\
\hline Great faith & .623 & & & & \\
\hline Promotional campaign & .608 & & & & \\
\hline Brand communication & .606 & & & & \\
\hline Patriosm/foreign culture & .578 & & & & \\
\hline Promise & & .778 & & & \\
\hline Cost concern & & .776 & & & \\
\hline Serve up to promise & & .761 & & & \\
\hline Reasonable price & & .760 & & & \\
\hline Latest technology & & .756 & & & \\
\hline Positive association & & .681 & & & \\
\hline Unique & & & .670 & & \\
\hline Hygiene & & & .660 & & \\
\hline Competing brand & & & .649 & & \\
\hline Alternative brand & & & .638 & & \\
\hline Advantage & & & .601 & & \\
\hline Innovative & & & .578 & & \\
\hline Good quality & & & .572 & & \\
\hline Lucrative packaging & & & .549 & & \\
\hline Identify with & & & & .799 & \\
\hline Proud & & & & .710 & \\
\hline Next time & & & & & \\
\hline Lifestyle & & & & & \\
\hline Maintain relationship & & & & & \\
\hline Recommendation & & & & & \\
\hline
\end{tabular}

Source: Own Field Survey, October-November, 2013 


\section{Naming of Factors, Brand Image of the Product and Cost and Commitment}

This study has identified five factors whose naming is very important. The factors have been named based on the variables clustered under a particular factor. It has also considered the loading of each variable (surrogate variable) for naming.

The first factor is named as brand image of the product. This factor explains the highest percentage of total variance which is 17.23 percent. Consumers' make most of their purchasing decisions of toiletries products considering their image in markets. Brand image depends on positive and warm feelings, trustworthiness, great faith, promotional campaign, brand communication and foreign culture. The variables meaning of brand carries maximum loading.

The second factor has been titled as cost and commitment of the organizations to convince Consumers' for purchasing their products. This factor can explain 16.98 percent of total variance in case of purchasing toiletries products. The maximum loading variable is promise and least one is positive association.

\section{Distinctiveness, Prestige and Customer Relationship}

Distinctiveness is identified as the third important factors Consumers' put priority when purchasing toiletries products. 15.63 percentage of total variance in toiletries product purchasing decision can be explained by this variable. The variable with highest loading is uniqueness and least loading is lucrative packaging.

The fourth factor is named as prestige or honor associated with purchasing a particular product. Although this factor does not bear high weight in purchasing

decisions of toiletries product but it substantially affects Consumers'. This study has found that this factor can explain 11.24 percent of total variance.

Customer relationship has been recognized as the last factors affect Consumers'. This factor can explain 8.21 percent of total variance. It is true that a large number of Consumers' decide buying any product considering relationship with organization. 
TABLE 5

ANOVA

\begin{tabular}{|l|l|c|c|c|c|c|}
\hline \multicolumn{7}{|c|}{ ANOVA } \\
\hline \multirow{4}{*}{ Brand Image } & $\begin{array}{c}\text { Sum of } \\
\text { Squares }\end{array}$ & df & $\begin{array}{c}\text { Mean } \\
\text { Square }\end{array}$ & F & Sig. \\
\hline & Between Groups & 6.728 & 4 & 1.682 & 1.699 & .152 \\
\cline { 2 - 8 } & Within Groups & 183.128 & 185 & .990 & & \\
\cline { 2 - 8 } & Total & 189.856 & 189 & & & \\
\hline \multirow{5}{*}{ Cost } & Between Groups & 3.235 & 4 & .809 & .807 & .522 \\
\cline { 2 - 8 } & Within Groups & 185.394 & 185 & 1.002 & & \\
\cline { 2 - 8 } & Total & 188.629 & 189 & & & \\
\hline \multirow{5}{*}{ Prestinctiveness } & Between Groups & 15.466 & 4 & 3.866 & 4.098 & .003 \\
\cline { 2 - 8 } & Within Groups & 174.534 & 185 & .943 & & \\
\cline { 2 - 8 } & Total & 190.000 & 189 & & & \\
\cline { 2 - 8 } & Between Groups & 1.577 & 4 & .394 & .388 & .817 \\
\cline { 2 - 8 } & Within Groups & 187.941 & 185 & 1.016 & & \\
\cline { 2 - 8 } & Total & 189.518 & 189 & & & \\
\hline \multirow{5}{*}{ Relationship } & Between Groups & 5.843 & 4 & 1.461 & 1.480 & .210 \\
\cline { 2 - 8 } & Within Groups & 182.619 & 185 & .987 & & \\
\cline { 2 - 8 } & Total & 188.461 & 189 & & & \\
\hline
\end{tabular}

Source: Own Field Survey, October-November, 2013

Analysis of Variance (ANOVA) has been used to identify whether consumers' perception differ according to their level of education. The underlying factors identified in this study are brand image, cost of products, hygienic conditions of products, prestige issues related to the products and relationships with consumers. These factors affect consumers to take purchase decision of toiletries products. ANOVA results present difference of opinions among individual with various level of education. 


\section{Findings}

This study has identified several factors which affect consumers to purchase square toiletries products. These factors are brand image, cost and commitment, distinctiveness, prestige and relationship. It has also identified that consumers differ in their opinion only on distinctiveness based on their educational level. But consumers' perceptions do not differ on factors which are brand image, cost and commitment, prestige and relationship. It signifies that consumers having different education levels consider these factors similarly when purchasing Squire Toiletries products. Among the considerable factors brand image of the product most significantly affects the consumers' purchasing behavior and the relationship with seller has the lowest effect.

\section{CONCLUSION}

The success of a company depends on its capability of identifying consumers' purchasing decision process along with the factors affecting that decision and tuning the company's offerings with that process and factors. Attraction and retention of consumers is a challenging task to the marketers. Different competitors offer different products to satisfy the needs of consumers by offering creative and attractive features. So, to create a distinctive position in the minds of target consumers the company should concentrate on the right value proposition of the offered product. Here right value proposition should be determined based on the target market's preference which is dynamic. So repositioning may be required. However the marketers should always be aware about consumers' preferred value proposition through the output of updated market research. 


\section{REFERENCES}

Al-Gahaifi, T. H., \& Světlík, J. (2011). Factors Influencing Consumer Behaviour in Market Vegetables in Yemen. Acta Universitatis Agriculturae et Silviculturae Mendelianae Brunensis, LIX (2), 17-28.

A Sajeevan Rao, R. K. (2010). "Bank selection Criteria Employed by MBA Students in Delhi: An Empirical Analysis”. Journal of Business Studies Quaterly, 1 (2), 5669.

Comrey, A.L. (1973). A First Course in Factor Analysis. San Diego: Academic Press.

Jennifer Keeling Bond, D. T. (2009). What Influences Consumer Choice of Fresh. Journal of Agricultural and Applied Economics, 41 (1), 61-74.

Ling, C. Y. (2013). Consumers' purchase intention of green products: an investigation of the drivers and moderating Variables. Elixir International Journal , 1450314509.

Md Reaz Uddin, T. K. (2013). Factors Affect the Success of SME in Bangladesh. Evidence from. Journal of Management and Sustainability, 3 (3).

Tinne, W. S. (2011). Factors Affecting Impulse Buying Behavior of Consumers at Superstores in Bangladesh. ASA University Review, 5 (1), 209-220.

Waleed Al-Ghaith, L. S. (2010). "Factors Influencing the Adoption and Usage of Online Services in Saudi Arabia". The Electronic Journal of Information System in Developing Countries, 40 (1), 1-32.

Yakup, D. D., \& Jablonsk, D. S. (2012). Integrated Approach to Factors Affecting Consumers Purchase. Global Journal of Management and Business Research, 12 (15), 60-87.

\section{Websites:}

www.itc.polyu.edu.hk/UserFiles/access/Files/BA/FYP1112/14090/09013452D.pdf. retrieved October 2013, from www.itc.polyu.edu.hk

www.wikipedia.com accessed on 05.10.2013

www.blog.compete.com accessed on 12.10.2013

www.blogspot.com accessed on 10.04.2014

www.ucdenver.com accessed on 10.04.2014 